\title{
Normobaric 0xygen Therapy for Pneumocephalus; Simple, Cheap, Available and Effective
}

\author{
Sigurd Fosmark ${ }^{1}$, Helene Engstrand Lier ${ }^{1,2}$, Karoline Skogen $^{3}$, Eirik Helseth ${ }^{1,4}$, Mads Aarhus ${ }^{1}$ and Jon Ramm- \\ Pettersen $^{1}$ \\ ${ }^{1}$ Department of Neurosurgery, Oslo University Hospital, Norway \\ ${ }^{2}$ Department of Neurology, Oslo University Hospital, Norway \\ ${ }^{3}$ Department of Neuroradiology, Oslo University Hospital, Norway \\ ${ }^{4}$ Institute of Clinical Medicine, Faculty of Medicine, University of Oslo, Norway
}

Submission: October 13, 2020; Published: May 03, 2021

*Corresponding author: Sigurd Fosmark, Department of Neurosurgery, Oslo University Hospital, Kirkeveien 166, 0450 Oslo, Norway

\begin{abstract}
Background: Pneumocephalus is quite often seen after traumatic brain injury and neurosurgical procedures. Though the majority of patients are asymptomatic, lethargy, headache, dizziness, decreased level of consciousness and neurological symptoms may all be signs of the condition. A suggested treatment is supplemental normobaric oxygen, a simple, cheap, available and effective treatment. As a reminder of this often forgotten treatment, we here present four cases with pneumocephalus treated with normobaric oxygen supplement. A short review of the theoretical basis for this treatment modality is also presented.

Methods: In this retrospective case series, we present four cases of pneumocephalus, all treated with normobaric oxygen supplement. Serial imaging using CT was applied for evaluation, and air volumes pre- and post-treatment were calculated.

Results: All cases showed decreased volumes of intracranial air after receiving supplemental $100 \% \mathrm{O}_{2}$ for $18-71$ hours with a volume reduction of the intracranial air ranging from $51.5 \%-98.2 \%$. In the three awake patients, radiographical volume reduction of the pneumocephalus was paralleled by clinical improvement. In one case the patient was on a ventilator during the normobaric oxygen treatment and clinical evaluation was not possible.
\end{abstract}

Conclusions: Our findings support the treatment of pneumocephalus with supplemental oxygen therapy.

Keywords: Pneumocephalus; Normobaric; Oxygen; Intracranial

\section{Introduction}

Pneumocephalus is commonly seen after intracranial procedures and traumatic brain injury. The vast majority of patients are asymptomatic; however, some experience headaches, lethargy, and focal neurological symptoms. In severe cases this condition can be life threatening. In the latter gas tends to accumulate bifrontally appearing as the classical Mount Fuji sign on head CT (computed tomography). This is indicative of a tension pneumocephalus, which may warrant immediate management [1]. Management options include surgical evacuation of air, hyperbaric oxygen treatment and normobaric oxygen therapy. Due to the urgency, the trend is often invasive and resource demanding procedures; while the simple, cheap, and readily available normobaric oxygen treatment is often forgotten. The evidence of its efficacy is scarce rendering it controversial. This treatment is examined through four patients from our institution with different underlying conditions for their substantial pneumocephalus. They all received supplemental normobaric oxygen treatment. In this case series, together with a review of the literature, we want to remind the clinicians of this simple, cheap, available and effective treatment.

\section{Methods}

Four cases of pneumocephalus treated at the Neurosurgical department at Oslo University Hospitals were included. They had different underlying conditions and three of them were secondary to neurosurgery. The initial volume (Vpre) of the pneumocephalus was measured on the head CT using Brainlab Elements/iPlan v. 3.0 (Brainlab AG, Olof-Palme-Str. 9, 81829 Munich, Germany) 


\section{Open Access Journal of Neurology \& Neurosurgery}

prior to normobaric oxygen treatment. The duration of the normobaric supplemental $\mathrm{O}_{2}$ differed between the patients. A pneumocephalus volume (Vpost) was measured on the control CT performed after normobaric oxygen treatment. From these values the difference in volumes for each patient $(\Delta V)$, and the rate of absorption $(\Delta \mathrm{V} / \mathrm{T})$ defined as change in volume per hour, as well as the rate in per cent per hour $(\% \mathrm{r} / \mathrm{T})$ was calculated.

\section{Case reports}

\section{Case 1}

A 69-year-old man with hypertension, previous NSTEMI and atypical Parkinsonism was admitted with a Glasgow Coma Score (GCS) of 13 and left-sided hemiplegia to his local hospital. Head
CT and MRI showed a primary brain tumour with haemorrhage. He was transferred to the neurosurgical department and a craniotomy was performed with complete resection of the tumour. The postoperative head CT showed a right-sided pneumocephalus with mass effect and midline shift with a volume of $120.6 \mathrm{~mL}$ (Figure 1a). Post operatively he also developed a pneumonia and his level of consciousness varied from a GCS 7-11. The pneumocephalus was managed with $25 \mathrm{~L} / \mathrm{min} 100 \% \mathrm{O}_{2}$ supplement on a mask with reservoir for $18 \mathrm{~h}$. His $\mathrm{pO}_{2}$ reached a peak level of $19 \mathrm{kPa}$. A control CT (Figure 1b) showed a reduction of the pneumocephalus volume to $58.4 \mathrm{~mL}$ and a decrease in the mass effect. This gives an absorption rate of $3.46 \mathrm{~mL} / \mathrm{h}$, or $2.86 \% / \mathrm{h}$. He was transferred back to the local hospital where he made a gradual partial recovery.
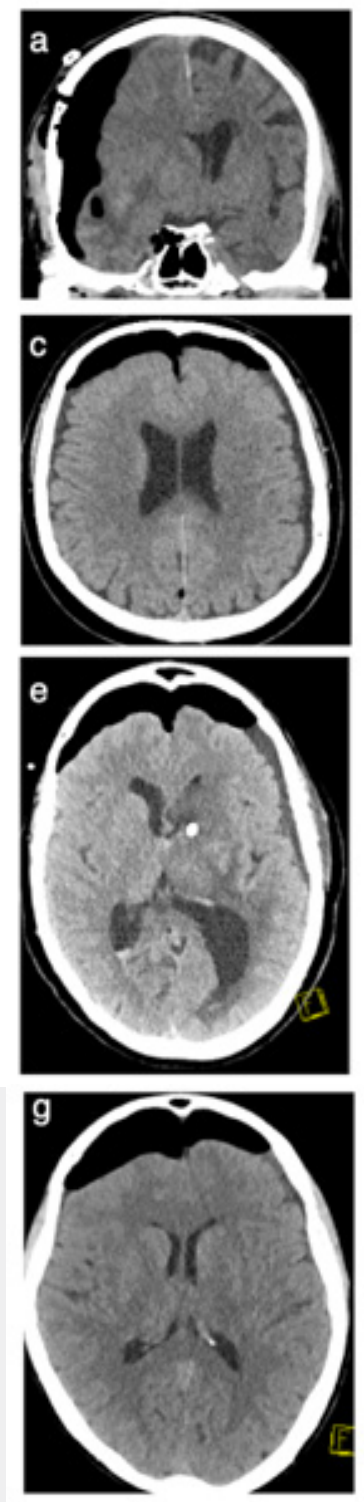
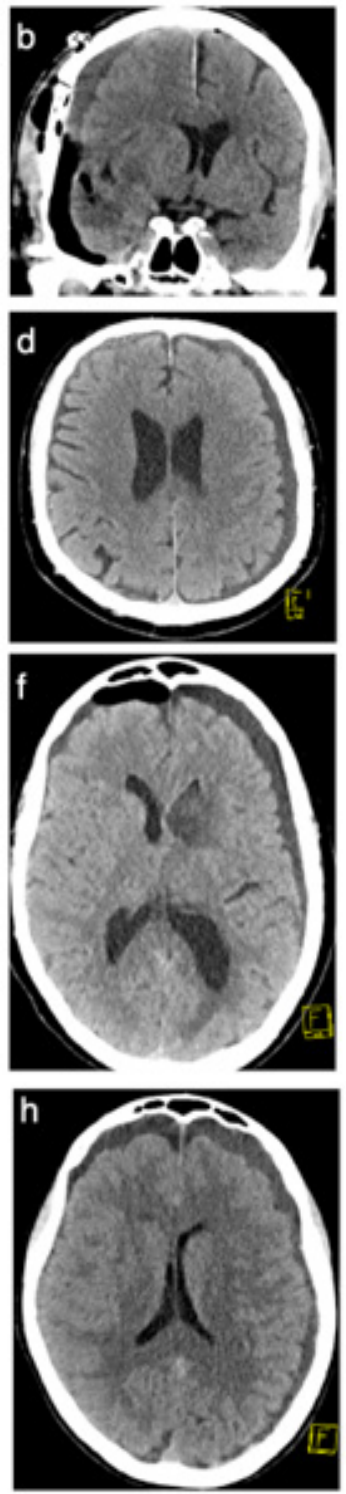

Figure 1: CT-scans before $(a, c, e, g)$ and after $(b, d, f, h)$ treatment with normobaric oxygen in patients 1 to 4 respectively. 


\section{Open Access Journal of Neurology \& Neurosurgery}

\section{Case 2}

A 75-year-old man with angina pectoris on acetylsalisylic acid fell and hit the back of his head on the ice 3 days prior to admission. He remained fully conscious after the fall, and he drove home himself after the incident. In the following days, he experienced an increasing headache and a dot feeling in his left ear together with reduced hearing. Repetitive Valsalva's maneuvers were performed to equalize the presumed increased pressure in the left ear. This resulted in a bubbling sensation in his head. The preceding day he went to his General Practitioner (GP) as the symptoms persisted in his left ear. The GP admitted him to the local hospital for further evaluation. A head CT revealed a fracture in the left temporal bone affecting the mastoid bone and consequently blood in the left middle ear. There was a $4 \mathrm{~mm}$ chronic subdural hematoma, frontal pneumocephalus of $61.4 \mathrm{~mL}$
(Table 1) with a tendency of a Mount Fuji sign, but no signs of herniation (Figure 1c). His acetylsalisylic acid was paused and he was transferred to the neurosurgical department. On arrival he was nauseous and on examination had a small cut in the back of his head, decreased hearing on his left ear and moderate leftsided hemotympanum. Further neurological examination was normal. The pneumocephalus was treated with $10 \mathrm{~L} / \mathrm{min} 100 \%$ $\mathrm{O}_{2}$ on a mask with reservoir. A control head CT after 12 hours of treatment showed some regression of the pneumocephalus, and he had improved clinically. He was treated for a total of 71 hours with $\mathrm{O}_{2}$. The $\mathrm{pO}_{2}$ was not measured during his treatment. On the final control CT there was a significant decrease in the pneumocephalus (Figure 1d) with a remaining pneumocephalus of $1.1 \mathrm{~mL}$, thus the absorption rate was $0.85 \mathrm{~mL} / \mathrm{h}$, or $1.38 \% / \mathrm{h}$ (Table 1). The presenting symptoms, exempting his left-sided hearing loss, regressed and he was discharged.

Table 1: Volumes and resorption rates of pneumocephalus in the four cases.

\begin{tabular}{|c|c|c|c|c|c|c|c|}
\hline Case & Vpre & Vpost & $\boldsymbol{\Delta V}$ & \%r(Reduced volume\%) & Treatment duration (T) & $\boldsymbol{\Delta V} / \mathbf{T}$ & \%r/T \\
\hline Patient 1 & $120.6 \mathrm{~mL}$ & $58.4 \mathrm{~mL}$ & $62.2 \mathrm{~mL}$ & $51.50 \%$ & $18 \mathrm{~h}$ & $3.46 \mathrm{~mL} / \mathrm{h}$ & $2.86 \% / \mathrm{h}$ \\
\hline Patient 2 & $61.4 \mathrm{~mL}$ & $1.1 \mathrm{~mL}$ & $60.3 \mathrm{~mL}$ & $98.20 \%$ & $71 \mathrm{~h}$ & $0.85 \mathrm{~mL} / \mathrm{h}$ & $1.38 \% / \mathrm{h}$ \\
\hline Patient 3 & $62.0 \mathrm{~mL}$ & $9.3 \mathrm{~mL}$ & $52.7 \mathrm{~mL}$ & $85 \%$ & $22 \mathrm{~h}$ & $2.40 \mathrm{~mL} / \mathrm{h}$ & $3.86 \% / \mathrm{h}$ \\
\hline Patient 4 & $128.0 \mathrm{~mL}$ & $34.5 \mathrm{~mL}$ & $93.5 \mathrm{~mL}$ & $73 \%$ & $28 \mathrm{~h}$ & $3.34 \mathrm{~mL} / \mathrm{h}$ & $2.61 \% / \mathrm{h}$ \\
\hline
\end{tabular}

Table abbreviations: Vpre: volume of pneumocephalus pretreatment, Vpost: volume of pneumocephalus post treatment, $\Delta \mathrm{V}$ : difference in volume of pneumocephalus pre and post treatment, \%r: reduction of pneumocephalus volume in per cent, T: treatment duration, $\Delta \mathrm{V} / \mathrm{T}$ : difference in volume of pneumocephalus pre and post treatment per unit of time (hours), \%r/T: reduction of pneumocephalus volume in per cent per unit of time (hours).

\section{Case 3}

This 63-year-old female patient with a history of fibromyalgia, depression and hypertension, treated with antihypertensive medicine was admitted to her local hospital after she collapsed in her own home. On site her GCS was 5 and she had a blown right pupil, hence she was intubated prehospitally. A head CT showed a left sided intracerebral haemorrhage with perforation into both lateral ventricles, third and fourth ventricles as well as the basal cisterns. An intracerebral CT angiogram did not reveal any vascular malformations. She was immediately transferred to the neurosurgical department for an evacuation of the haemorrhage with a left sided craniotomy and placement of an External Ventricular Drain (EVD). Postoperatively she remained intubated and the post operative head CT the next day showed a pneumocephalus of $62 \mathrm{~mL}$ with the Mount Fuji-sign (Figure 1e). The pneumocephalus was managed with $100 \% \mathrm{O}_{2}$ on a ventilator for approximately 22 hours. Her $\mathrm{pO}_{2}$ was raised to $52 \mathrm{kPa}$ during this time. The control head CT (Figure 1f) at this time revealed a considerable reduction of the pneumocephalus to $9.3 \mathrm{~mL}$ giving an absorption rate of $2.40 \mathrm{~mL} / \mathrm{h}$, or $3.86 \% / \mathrm{h}$ in relative terms. A new head CT four days later showed almost complete regression of the pneumocephalus. She was discharged to rehabilitation with neurological deficits consisting of a right-sided hemiparesis and dysphasia.

\section{Case 4}

An 82-year-old woman with hypertension, osteoporosis and psoriasis on acetylsalisylic acid suffered from headaches and unsteadiness for 3 months. A head CT revealed bilateral Chronic Subdural Hematomas (CSDH) with compression of the lateral ventricles and decreased surface relief. Acetylsalisylic acid was paused for one week and the CSDH were evacuated with bilateral single burr holes. There were no perioperative complications. Postoperatively her GCS score fell to 11 . The head CT showed a bifrontal pneumocephalus of $128.0 \mathrm{~mL}$ with mass effect (Figure $1 \mathrm{~g})$. No action was taken at this time. The consecutive day she developed an intermittent total AV-block with a 10 second pause which was treated with a pacemaker. Her GCS then fell to 5 after this and the pneumocephalus was aspirated through the subdural drains with an immediate effect, and her GCS increased to 13 , however her level of consciousness varied. There was still a large pneumocephalus on a control head CT. She was further managed with intermittent Opti flow and then $10 \mathrm{~L} / \mathrm{min} 100 \%$ $\mathrm{O}_{2}$ on a mask for $28 \mathrm{~h}$ giving her a max $\mathrm{pO}_{2}$ of $58 \mathrm{kPa}$. The final control head CT (Figure 1h) showed a considerable reduction of the pneumocephalus to $34.5 \mathrm{~mL}$ along with good clinical progress. This gives an absorption rate of $3.34 \mathrm{~mL} / \mathrm{h}$ or $2.61 \% / \mathrm{h}$. On return to her local hospital she had a GCS of 15 and a slight headache. 


\section{Discussion}

In this case series we present four patients with differing aetiologies for pneumocephalus, all treated with normobaric oxygen therapy. All four cases had imaging improvement with decreased amount of intracranial air, ranging from 51.5-98\% volume reduction (Table 1). The absorption rate varied from 1.38$3.86 \% / \mathrm{h}$. These results are similar to ones obtained by Gore et al who reported a mean absorption rate of $2.7 \% / \mathrm{h}(1.7-3.7 \% / \mathrm{h})$ in a small prospective case-control study with normobaric oxygen for non-tension pneumocephalus [2]. Pneumocephalus may be caused by trauma, infection or intracranial surgery. In most cases no action is needed, however in rare cases patients may experience a variety of neurological symptoms, commonly lethargy, headache, nausea and altered mental status and if severe it can be a life threatening condition. Intracranial air can accumulate in any space within the cranial vault, but most commonly it occupies the subdural space [3] and generally accumulates bi-frontally, causing the classic and characteristic Mount Fuji sign on a head CT $[1,4]$. This may be caused by either tension or non-tension pneumocephalus. Tension pneumocephalus may arise when a valve like fistula between the extracranial and intracranial space allows air to move in but not out of intracranial space. Air will then be trapped within the cranial vault. It may also appear after cranial surgery in the rare cases of $\mathrm{N}_{2} \mathrm{O}$ anaesthesia which increases the intravascular partial pressure of nitrogen $[5,6]$. As this is a neurosurgical emergency, immediate surgical intervention is often warranted. However, in the case of non-tension pneumocephalus it is easy to forget the simple, cheap, available and effective supplemental normobaric $\mathrm{O}_{2}$ which was given to all patients in our series.

The pneumocephalus is made up of atmospheric air which constitutes mainly of oxygen and nitrogen, with the latter posing the largest part of the two gases, $21 \%$ vs $79 \%$ respectively. Removing nitrogen would decrease the volume to a larger extent than removing any other gas component. Increasing the partial pressure of oxygen within the cerebral arterial blood creates a concentration gradient of nitrogen to cross over the endothelium of cerebral vessels, as oxygen suppresses nitrogen within the blood. Hence the nitrogen diffuses into the blood and is transported to the lungs where it is exhaled [7]. This was described by Dexter and Reasoner who found that an increase in the fraction of inspired oxygen $\left(\mathrm{FiO}_{2}\right.$ ) from 0.21 (atmospheric oxygen pressure at sea level) to 0.4 increased the absorption velocity of nitrogen with $67 \%$. Further increase in $\mathrm{FiO}_{2}$ gave only minor increase in nitrogen absorption. Based on mathematical models they found the optimal $\left(\mathrm{FiO}_{2}\right)$ to be 0.4 , reaching close to plateau absorption velocity with minimal risk [7]. Our patients all received $100 \%$ $\mathrm{O}_{2}$, hence we did not look further into this matter. The $\mathrm{pO}_{2}$ was measured in three patients, but not in case 3 . The maximum values differed from $19 \mathrm{kPa}$ to $58 \mathrm{kPa}$. This direct measure of the arterial partial pressure of oxygen is, unlike $\mathrm{FiO}_{2}$, independent of lung function. Finding an optimal value of $\mathrm{pO}_{2}$ for patients with pneumocephalus may be helpful to guide treatment. It was further described that the absorption rate decreased with decreasing size of the pneumocephalus, making the time-absorption relationship non-linear [7]. This can explain the common practice of an initial $24 \mathrm{~h}$ management and then re-evaluation after a control head CT. The patients presented here had a varying absorption rate which may be explained by different delivery methods. In case 3 the patient received oxygen while on a ventilator, which may have played a role in the high absorption rate of $3.86 \% / \mathrm{h}$. In case 2 the patient was treated for 71 hours, and there was no radiographic control between 12 and 71 hours of treatment since the patient was improving. Thus, there is not any assessment of the pneumocephalus between these times. Considering the nonlinear absorption rate described earlier [7], there is a chance the pneumocephalus may have been close to reabsorbed in the time between the two control head CTs. We present four cases of pneumocephalus of which three are after cranial surgery and one has a rather special traumatic mechanism. Based on our experience large pneumocephalus is rarely seen after trauma, but in this case the patient forced air through a dural defect by repeatedly performing Valsalva's maneuver.

The modes of increasing the partial pressure of oxygen within the cerebral arteries are typically normobaric as in this case series, either by nasal catheter or a mask. Some argue that in severe cases hyperbaric oxygenation should be considered $[8,9]$, as this increases the absorption velocity, while others have suggested efficient treatment with high-flow $\mathrm{O}_{2}$ through a nasal cannula [6]. Exempting case 3 in our series, where the patient was treated while unconscious and intubated, the remaining cases all had symptoms that could be prescribed to the pneumocephalus, and all seemingly had good clinical effect of the treatment. This supports the somewhat controversial current therapy with oxygen for pneumocephalus. The treatment is cheap, simple, readily available and may even be applied in hospitals without a neurosurgeon. The duration of treatment remains controversial, reflected in our cases where the treatment duration varied from 18-71 hours. Pneumocephalus is a well-known condition in the neurosurgical department, it seems reasonable that its treatment should be thoroughly investigated and well-founded. As mentioned, the delivery method and aggressiveness of oxygen therapy also varies, ranging from normobaric oxygen through nasal catheter to the more extreme hyperbaric oxygenation, and herein lies another potential for further investigation.

\section{Limitations}

The cases presented here were treated with normobaric oxygen therapy, but with different delivery methods, a mask, with or without reservoir, or a ventilator. This might have influenced the absorption velocities. The treatment duration differed between cases, and the optimal duration was not further investigated. Age, background and medical history, such as lung function, varied between patients. There were no controls in our series 
and thus resolution of pneumocephalus without supplemental $\mathrm{O}_{2}$ may not be excluded, and the absorption rate in such cases were not assessed. Hence a randomized controlled trial should be performed to assess these points.

\section{Conclusion}

The four cases presented in this article support the use of supplemental normobaric $\mathrm{O}_{2}$ for the treatment of pneumocephalus, a simple and effective treatment that should be part of the neurosurgical armamentarium.

\section{Consent}

The patients or their closest relatives have given their informed consent for the publishing of case reports.

\section{References}

1. Michel SJ (2004) The Mount Fuji sign. Radiology 232(2): 449-450.

2. Gore PA, Maan H, Chang S, Pitt AM, Spetzler RF, et al. (2008) Normobaric oxygen therapy strategies in the treatment of postcraniotomy pneumocephalus. J Neurosurg 108(5): 926-929.
3. Dabdoub CB, Salas G, Silveira Edo N, Dabdoub CF (2015) Review of the management of pneumocephalus. Surg Neurol Int 6: 155.

4. Ishiwata Y, Fujino H, Kubokura T, Tsubone K, Sekino T, Fujitsu K (1987) [Subdural tension pneumocephalus following surgery of chronic subdural hematoma]. No Shinkei Geka 15(4): 419-424.

5. Reasoner DK, Todd MM, Scamman FL, Warner DS (1994) The incidence of pneumocephalus after supratentorial craniotomy. Observations on the disappearance of intracranial air. Anesthesiology 80(5): 10081012.

6. Siegel JL, Hampton K, Rabinstein AA, McLaughlin D, Diaz-Gomez JL (2018) Oxygen Therapy with High-Flow Nasal Cannula as an Effective Treatment for Perioperative Pneumocephalus: Case Illustrations and Pathophysiological Review. Neurocrit Care 29(3): 366-373.

7. Dexter F, Reasoner DK (1996) Theoretical assessment of normobaric oxygen therapy to treat pneumocephalus. Anesthesiology 84(2): 442447.

8. Paiva WS, de Andrade AF, Figueiredo EG, Amorim RL, Prudente M, et al. (2014) Effects of hyperbaric oxygenation therapy on symptomatic pneumocephalus. Ther Clin Risk Manag 10: 769-773.

9. Lundborg M, Helseth E, Josefsen R, Braathen M, Skogen K, et al. (2018) Hyperbaric oxygen therapy of air embolus in the cerebral venous sinuses after intracranial surgery: a case report. Acta Neurochir (Wien) 160(7):1401-1405.

\section{Your next submission with Juniper Publishers will reach you the below assets}

- Quality Editorial service

- Swift Peer Review

- Reprints availability

- E-prints Service

- Manuscript Podcast for convenient understanding

- Global attainment for your research

- Manuscript accessibility in different formats

( Pdf, E-pub, Full Text, Audio)

- Unceasing customer service

Track the below URL for one-step submission

https://juniperpublishers.com/online-submission.php 